\title{
The State of South African Mathematics Education: Situating the Hidden Promise of Multiple-solution Tasks
}

\author{
Sfiso Cebolenkosi Mahlaba ${ }^{1 *}$ \\ ${ }^{1}$ North-West University, SOUTH AFRICA
}

Received 2 July 2020 - Accepted 13 November 2020

\begin{abstract}
We live in the challenging times of the 21st-century with the increased need for humans to possess specific skills that will help them to be successful in this era. This means that education should in learners, develop these skills effectively. Different global countries have begun to recognize the significance of multiple solutions tasks in the teaching and learning of mathematics in the 21st-century. However, this practice is not visible in South Africa. Hence, the current study explores and synthetize the sparsely available literature on MSTs to answer the question: What is the significance of multiple-solution tasks (MSTs) in mathematics education and why is it relevant for South African mathematics education to make the exercise of producing multiple solutions accessible to learners? The literature that is being synthetized here is viewed through the optic lens of the social constructivism theory as proposed by Vygotsky and explicated in Jean Lave and Etienne Wenger's Situated learning: Legitimate peripheral participation. In the conclusion I engage in an argumentation that illuminates the significance of MSTs in mathematics education and provide reasons why it would be beneficial for the South African mathematics curriculum to incorporate MSTs.
\end{abstract}

Keywords: multiple solution tasks, problem solving, creativity, geometry

\section{INTRODUCTION AND PROBLEM STATEMENT}

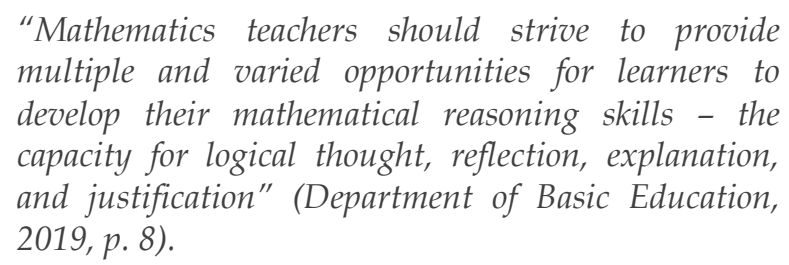

This theoretical article explores the power of mathematical problem-solving in the development of mathematical knowledge, thinking and reasoning. It puts the development of advanced mathematical thinking and mathematics-specific 21st-century skills, like creativity, at the centre of mathematical problemsolving, from routine to non-routine problem-solving. A good problem should always allow problem-solvers to compute multiple solutions. Such problems are referred to as multiple-solution tasks (MSTs). MSTs allow problem-solvers to present multiple solutions or multiple proofs of a problem (Levav-Waynberg \& Leikin, 2012b). These multiple solutions differ in their "representations of a mathematical concept, ... properties (definitions or theorems) of mathematical concepts from a particular mathematical topic, ... mathematical tools and theorems from different branches of mathematics, or ... tools and theorems from different subjects (not necessarily mathematics)" (Leikin, 2014, pp. 68-69). Furthermore, MSTs have different solution spaces: an individual solution space representing all sets of solutions generated by a single person without the assistance of another person; a collective solution space representing solutions generated by a group of people working together; and an expert solution space produced by expert mathematicians (Leikin, 2014; LevavWaynberg \& Leikin, 2012b). The requirement of multiple solutions to a problem transforms it from being a routine problem to a challenging task which requires more insight and multiple-solution strategies (Leikin, 2014; Silver, 1997) because computing multiple solutions to a problem requires reflective (Dewey, 1933) and higher 


\section{Contribution to the literature}

- This study dissects the literature done on multiple solutions tasks globally and positions multiple solutions as an option to teach mathematical problem solving in South Africa.

- The study identifies a gap that South African mathematics education and mathematics education research has not considered the use of multiple solutions tasks to teach mathematics.

order $^{1}$ (Miri et al., 2007; Resnick, 1987) thinking. Encouraging learners to construct multiple solutions for a problem is considered an attribute of high-quality teaching (National Council of Teachers of Mathematics, 2000). Theoretically, the use of MSTs is well-founded in mathematics and mathematics education. Polya (1973) acknowledges that problems are better understood by using two or more proofs which allow further understanding of the problem and viewing it from different perspectives. Furthermore, mathematical thinking and reasoning can be fostered by showing different paths to solving mathematical problems (Schoenfeld, 1985). Dhombres (1993) argued that one proof is not always enough because of the universality of mathematics as a domain - various approaches are required. Recent educational transformations in different countries have recommended that mathematics learners be exposed to multiple methods of solving mathematical problems (Department of Basic Education, 2019; Große, 2014; National Council of Teachers of Mathematics, 2000; Rittle-Johnson, Star, \& Durkin, 2012). However, South African teachers still do not value learners' multiple solutions, have difficulty in grading them (Bingolnali, 2011; Mhlolo, 2017) and might not be aware of the benefits of nurturing multiple-solution strategies in learners.

Active learning, critical and creative thinking, high knowledge and skills are some of the basic principles of the Curriculum and Assessment Policy Statement (CAPS) (Department of Basic Education, 2011). Furthermore, the Department of Basic Education (DoBE) sees mathematics as a human activity in which both teachers and learners actively engage in solving societal problems (Department of Basic Education, 2011, 2019). A recent document from the DoBE has highlighted the significance of multiple solutions in mathematics through the framework for teaching mathematics for understanding (Department of Basic Education, 2019). However, South Africa has a longstanding trend of poor performance in both national and international tests. The country has been ranked second last in the recent Trends in Mathematics and Science Study (TIMMS) (Reddy et al., 2016). While results from the Southern and Eastern Africa Consortium for Monitoring Educational Quality (SACMEQ) show improvement in Rasch scores of South African learners' performance in mathematics
(Department of Basic Education, 2017), the World Economic Forum (2015) has ranked South Africa the lowest in higher education mathematics and science education. Different factors influencing poor mathematics performance have been investigated in local studies, from language and learners' background information (Howie, 2003; Phakeng \& Moschkovich, 2013), home and school resources (Visser, Juan, \& Feza, 2015) to teacher classroom practice (Arends, Winnaar, \& Mosimege, 2017) and other perspectives. As useful as they are, the suggestions from these studies are limited as regards their classroom applications. In this article, I argue for an unchartered territory in South African mathematics education as a possible approach to enhance learners' problem-solving skills, critical thinking and higher-order thinking - that is, nurturing the production of multiple solutions to mathematical problems. While the emphasis of this article is on problem-solving as a 21st-century skill that has been on the mathematical agenda for several years, my approach is new and has not been empirically tested in both teachers and learners within the context of South Africa. In this article, I address the following question: What is the significance of multiple-solution tasks (MSTs) in mathematics education and why is it relevant for South African mathematics education to make the exercise of producing multiple solutions accessible to learners?

\section{MULTIPLE SOLUTION TASKS (MSTs)}

In George Polya's formulation of mathematical problem-solving heuristic, he mentions the looking back stage where learners are encouraged to reflect on their solutions and search for alternative solutions (Polya, 1973). This highlights the process of reflecting as critical during mathematical problem-solving. Reflection kindles metacognition - another integral part of problem-solving (Flavell, 1976, 1979; Schoenfeld, 1985, 1992) - that is promising in nurturing multiple solutions. Engaging in the activity of producing multiple solutions through MSTs allows learners to practice nonroutine problem solving, showcase their creative and critical thinking and most importantly construct their own knowledge, all of which are activities learners can be engaged in to develop higher order mathematics thinking skills (Apino \& Retnawati, 2017). The use of MSTs in mathematics education has been shown to have

\footnotetext{
1 "Higher order thinking can be conceptualised as a non-algorithmic, complex mode of thinking that often generates multiple solutions" (Miri, David, \& Uri, 2007, p. 355). In his characterization of higher order thinking skills, Resnick (1987) mentions multiple criteria and solutions, selfregulation and effortful, all of which are characteristics that are closely linked to self-directed learning, a global imperative for the 21st-century.
} 
a positive influence on learners' development of different mathematical competencies and may be used to assess some mathematical abilities. Hence, in the following sections, I discuss the benefits of incorporating MSTs in mathematics education as they appear from the sparse existing literature on MSTs and mathematics education. I focus mainly on the benefits of MSTs on mathematical creativity and problem solving with a particular example of a multiple solution task in geometry. Thereafter, I change my focus to the South African context, indicating the state of research on MSTs and how can incorporating MSTs in mathematical activity benefits South African learners in particular.

\section{Mathematical Giftedness and Creativity}

There is a vast amount of literature on creativity; amongst others, is Hadamard (1945), who attempted to explain his conceptualisation of his mathematical theories. Despite numerous studies investigating creativity and mathematical creativity, a precise scientific definition of the construct seems to be lacking (Anderson, 1960; Mann, 2006). To describe creativity, Poincare (1948) used the metaphor of choice, while Anderson (1960) perceives creativity as reflecting original unique thought. For some, creativity is related to divergent thinking (Cropley, 1997; Guilford, 1967), while for others, it is the complex interrelationship between divergent and convergent thinking (Runco, 1993). Divergent thinking has been investigated in a plethora of studies concerned with mathematical originality. Testing divergent thinking through psychometric tests gives an idea of one's creative potential, but performing well in such tests does not guarantee creativity (Runco \& Acar, 2012; Sriraman, 2005). Most divergent thinking tests focus on fluency one's ability to provide numerous ideas on a specific subject - as the main measure of creativity (Runco \& Acar, 2012). What seems to link to this conceptualisation of fluency is Polya's (1954) emphasis on utilising various heuristics in solving mathematical problems. Currently, the literature on mathematics education works with functional definitions of creativity (Ervynck, 1991; Sriraman, 2009; Torrance, 1966). The problem with obtaining a precise definition of creativity is explained clearly in the work of Sriraman (2009) and other related studies. Hence, in this article, that avenue is not taken. In all these working definitions of creativity, "originality" is central in showing creativity (Runco \& Acar, 2012). Here, I conceptualise mathematical creativity as the exercise of producing multiple varied, novel solutions to mathematical problems.

Creativity has long been characterised as a trait of being gifted (Renzulli, 2011). Hence, teachers need to be aware of traits resembling giftedness in learners (Mhlolo, 2017). According to Renzulli (2011), giftedness occurs at the intersection of three traits: creativity, task management, and above-average ability. Giftedness is a multifaceted concept in which creativity is but one part of assessing giftedness in mathematics education. A clear explanation of the latter claim is articulated by Winner (2000), Sriraman (2005), Leikin (2010). Sriraman, Haavold, and Lee (2013), Leikin and Pitta-Pantazi (2013), and Leikin and Lev (2013), amongst others. Again, these studies are not deeply analysed because one can access any of these articles and acquaint oneself with the explanations; hence my choice of just highlighting these studies. While most studies conceptualise giftedness in terms of above-average ability and IQ tests (Leikin, 2007; Leikin \& Lev, 2013; Pfeiffer \& Blei, 2008), I adopt the view that creativity is an important trait of giftedness, one that can be natured through incorporating MSTs in mathematics education.

Early studies on creativity associated it with ingenuity possessed by rare individuals with exceptional thought processes (Weisberg, 1988) - a "quality of protoplasm" (Anderson, 1960, p. 10). However, studies indicated that creativity can be natured in all human beings with careful planning and implementation of material designed to facilitate the process (Silver, 1997; Sriraman, 2009). In particular, mathematical problem-solving is the main tool that can nurture mathematical creativity (Pehkonen, 1997; Silver, 1997). Hashimoto (1997) discusses methods of fostering mathematical creativity that are all based on problemsolving. However, one ought to recognise that problemsolving has been conceptualised differently in mathematics education research. Therefore, in this case, I focus on problem-solving of both clearly defined, routine, ill-posed and non-routine mathematical problems because I only aim to position the production of multiple solutions as important in the development of mathematical thinking. Furthermore, the requirement of multiple solutions positions an algorithmic problem as a non-routine problem that requires more insight into and understanding of the constituents of the problem (Leikin, 2010). Furthermore, Silver (1997) and Sriraman (2005) suggest that the incorporation of ill-structured mathematical problems can promote learners' production of multiple solutions, in turn, developing their mathematical creativity.

The utilisation of MSTs has been studied from different perspectives, and here I give a glance at the outcomes of such studies on mathematical creativity. Levav-Waynberg and Leikin (2012a) incorporated MSTs in 11 classes comprising 229 students so as to measure development in their geometrical knowledge and creativity and compared the results with a control group. They used connectedness and correctness to measure learners' geometrical knowledge and fluency, flexibility and originality to measure learners' creativity. They found that the incorporation of MSTs improved learners' geometrical knowledge and creativity, influencing connectedness, fluency and flexibility without an observable change in learners' originality (Levav- 
Waynberg \& Leikin, 2012a). In the same project, LevavWaynberg and Leikin (2012b) concluded that the MST geometry tool used in their study could be used to stratify learners according to their required level of instruction. A study conducted by Guberman and Leikin (2013) indicated that the incorporation of MSTs is effective in the development of pre-service mathematics teachers' systematic and craft modes. Their study presents evidence that both low-performing and highperforming pre-service mathematics teachers can benefit greatly from the incorporation of MSTs (Guberman \& Leikin, 2013). MSTs present teachers with a window they can use to investigate and realise learners' mathematical potential at different complexity levels of mathematical problem-solving (Leikin, 2014). After a careful analysis of students working on MSTs, Schindler, Joklitschke, and Rott (2018) proposed that, in mathematics, creativity should be viewed as a sub-domain, hinting at the existence of geometry creativity or algebraic creativity. Hence, MSTs can be used not only to nuture learners' mathematical creativity and problem-solving (De Villiers, 2016, 2017; Pillay, 2017; Samson, 2015, 2017) but also to evaluate their creative ability and geometry knowledge (Leikin \& Lev, 2013; Levav-Waynberg \& Leikin, 2012b). Creativity has been recognised as one of the important skills to possess in the 21st century together with problem-solving (Mhlolo, 2017; Organization for Economic Co-operation and Development, 2018). Nurturing creativity as a source of innovation (Mhlolo, 2017) in learners should therefore be the goal of mathematics education in the 21st century. As a critical component of advanced mathematical thinking and mathematical discovery (Ervynck, 1991), nurturing mathematical creativity in learners through MSTs can enhance their mathematical thinking.

\section{Developing Mathematical Thinking and Problem- solving}

De Villiers and Heideman (2014) expand on Lockhart's (2009) lament that school mathematics is usually far from the activity of mathematicians. Their concluding remarks about Albert Einstein's quotes, though humorous, are indeed a reflection of the activity of mathematicians, and they directly relate to the activity of seeking multiple solutions to mathematical problems. De Villiers and Heideman stress the significance of exploration in mathematical activity (De Villiers \& Heideman, 2014), an activity that is usually employed in seeking multiple solutions to mathematical problems (Santos-Trigo \& Reyes-Rodriguez, 2016). They place explorations as important in the growth of mathematical thinking during problem-solving (Samson, 2015, 2017; Samson \& Kroon, 2019). Problem-solving is further important not only in developing creative thinking in mathematics but also in mathematical thinking as a domain-specific type of thinking (Schoenfeld, 1985, 1992). The development of mathematical thinking in schools is facilitated by the curriculum, but mainly by teachers in their respective classrooms in different ways. One approach involves the utilisation of MSTs in mathematical instruction. De Villiers $(2016,2017)$ asserts that the processes of reflecting during problem-solving can enhance one's mathematical thought and problemsolving ability. Problem-solvers' prior knowledge as a resource brought into the problem-solving scenario is useful because the production of multiple solutions in mathematics requires some degree of mathematical knowledge acquisition (Schindler et al., 2018; Schoenfeld, 1985). MSTs encourage learners to use different strategies to solve mathematical problems and prove to improve their success in future mathematical problem-solving (Erbas \& Okur, 2012). Encouraging learners to pursue multiple solutions to mathematical problems can improve their effectiveness and flexibility in solving such problems (Daher, Tabaja-Kidan, \& Gierdien, 2017; Levav-Waynberg \& Leikin, 2012a, 2012b; Stanislaw \& Krug, 2014) even though it does not always affect their performance in mathematics (Schindler et al., 2018; Schukajlow, Krug, \& Rakoczy, 2015). Furthermore, utilising MSTs allows more potentially creative learners to present their creative solutions to problems (LevavWaynberg \& Leikin, 2012a; Sriraman \& Dickman, 2017). Deductive reasoning and critical thinking skills are important in geometry problem-solving and in the 21st century, and the use of MSTs can improve these skills (Segal, Stupel, \& Flores, 2017; Sriraman \& Dickman, 2017). MSTs can also be used as a strategy to develop young mathematicians who can thrive in the fourth industrial revolution (4IR), relying on their ability to use different solution strategies to solve problems.

\section{The Significance of MSTs in Geometry Education}

Challenging learners mathematically is at the core of developing their mathematical thinking and equipping them with various 21st-century mathematical skills. Euclidean geometry is one area in which most South African learners and teachers struggle the most (Alex, 2019; Alex \& Mammen, 2014; Naidoo \& Kapofu, 2020; Stols, Van Putten, \& Howie, 2010; Ubah \& Bansilal, 2019). However, it is an area in which MSTs and mathematical challenge are always present (Leikin, 2014; Stupel \& BenChaim, 2017). Due to the dire situation of poor performance in geometry-related tasks and teachers struggling with teaching geometry successfully, different measures have been taken to remedy the situation in South Africa, for example, the use of a geometry software (Bayaga, Mthethwa, Bosse, \& Williams, 2019; De Villiers, 2004b; Stols et al., 2015; Umugiraneza, Bansilal, \& North, 2018), but in most cases, schools are under resourced and teachers are not proficient in using geometry software for teaching. Other attempts include providing teachers with professional development opportunities - like the Wits Maths Connect Secondary (WMCS) project - with aims 
to improve the quality of mathematics teachers (Pournara, Hodgen, Adler, \& Pillay, 2015). However, the situation has not improved significantly. Recent studies and analyses of national marking guidelines of Grade 12 Paper 2 in South Africa have shown that multiple solutions exist in Euclidean geometry problems, some of which are not initially evident to others. As such, geometry allow for the production of different proofs and solutions - standard, elegant and proofs without words (Sigler, Segal, \& Stupel, 2016). Another potent approach to geometry teaching is the incorporation of dynamic geometry software (DGS) (such as geometers Sketchpad, Cabrii or GeoGebra) which allows for explorations, conjecturing and proofs (De Villiers, 2004a, 2004b). Exploring geometry conjectures in a DGS may lead to different conclusion, some correct, some not, and some a new discovery, and proving these conjectures may be the central activity of producing multiple solutions. Producing multiple solutions to geometry problem in the classroom may invoke excitement and wonder in learners instead of producing just one which can leave them in awe (Stupel \& Ben-Chaim, 2017). In this section I want to present different solutions to a particular geometry problem to support that Euclidean geometry is a goldmine of multiple solutions. I do not want to make universal conclusions about this phenomenon but to awaken the need to nurture mathematical creativity in our learners through geometry MSTs. In doing so, I will use a problem (Problem 1.7) I came across in a book by Chen (2016, p. 5) titled Euclidean geometry in mathematical Olympiads.

\section{THE PROBLEM}

Let $\mathrm{O}$ and $\mathrm{H}$ denote the circumcentre and orthocentre of an acute triangle $\mathrm{ABC}$ respectively. Show that $\angle B A H=\angle C A O$.

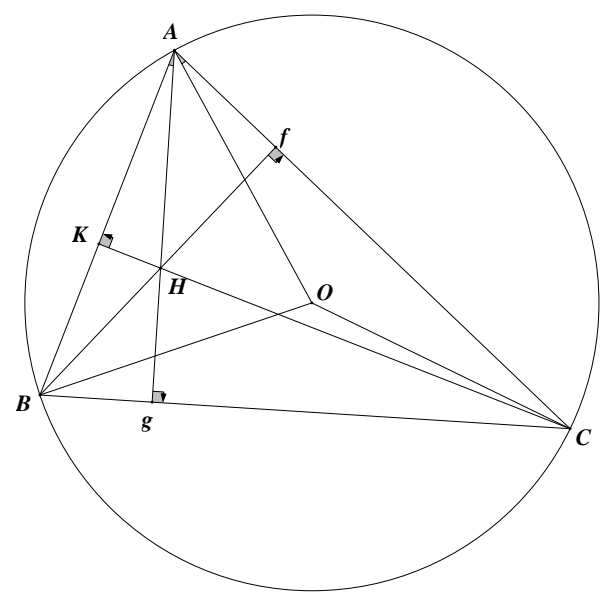

Figure 1. The Problem

Learners who have acquired the definition of the circumcentre can use isosceles triangles and the angle at the centre theorem to prove the result. This problem is equivalent to showing that $\angle A B H=\angle C B O$.

\section{Multiple Solutions/Proofs for this Problem}

Solution 1: Obtained through exploration in Geometer's Sketchpad

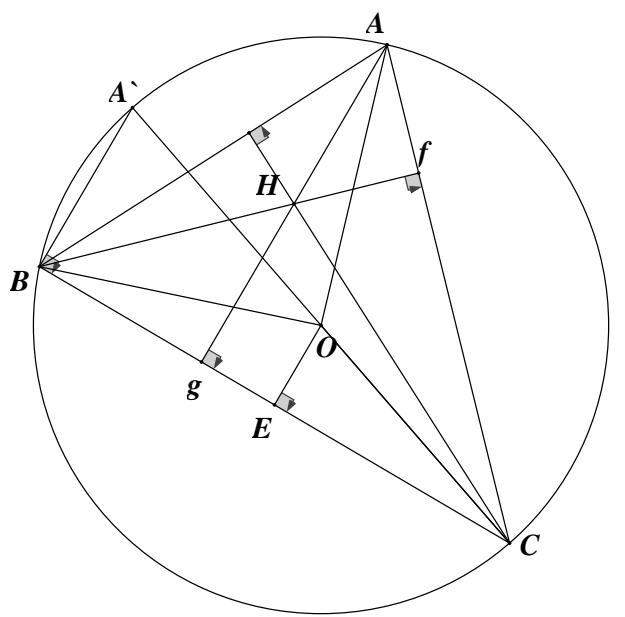

Extend $\mathrm{CO}$ to meet the circumcircle at $\mathrm{A}$. Then $\angle B A^{\prime} C=\angle B A C=x$, since they are inscribed in chord BC. Hence, from similarity $\left[\triangle B A^{\prime} C\right.$ III $\left.\triangle E O C\right]$ (or corresponding angles) $\angle E O C=\angle A=x$. Therefore, since $\triangle O B C$ is an isosceles, $\angle O B C=90^{\circ}-x=\angle O C B$. But $\angle A B f=90^{\circ}-x$, since $\angle A B F=90^{\circ}$. Thus, $\angle A B H=$ $\angle A B F=90^{\circ}-x=\angle O B E=\angle O B C$. QED. Similarly, we can prove that $\angle A B H=\angle C A O$ and $\angle B C H=\angle A C O$, and thus $\angle B A H=\angle C A O$.

\section{Solution 2}

From the diagram in Figure $1, \angle B O C=2 \angle A$, since the angle at the centre of a circle is twice the angle at the circumference. In $\triangle B O C, \angle B O C+\angle O B C+\angle O C B=180^{\circ}$ (sum of angles in a triangle), but $\angle O B C=\angle O C B$ (angles opposite equal sides of a triangle), $\therefore 2 \angle A+2 \angle O B C=$ $180^{\circ}$, which simplifies to $2(\angle A+\angle O B C)=180^{\circ}, \therefore$ $\angle O B C=90^{\circ}-\angle A$. Then in $\triangle A B f, 90^{\circ}+\angle A+\angle A B H=$ $180^{\circ}$ (sum of angles in a triangle), making $\angle A B H$ the subject of the equation, we have $\angle A B H=180^{\circ}-90^{\circ}-$ $\angle A, \therefore \angle A B H=90^{\circ}-\angle A=\angle O B C$. Similarly, we can show that $\angle B A H=\angle C A O$. QED.

Solution 3

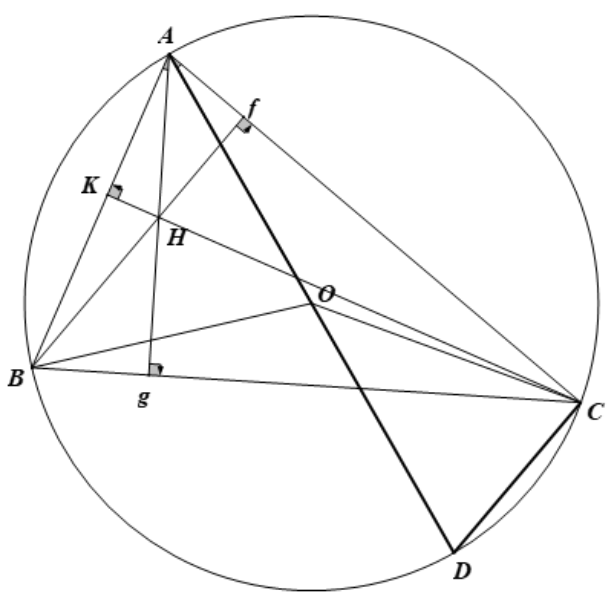

Another approach that involves a construction would be when one extends $A O$ to $D$ on the circumference and 
join $C D$. Then, $\angle A C D=90^{\circ}$ because of the angle in a semicircle. If we let $\angle C A O=x$, then $\angle A D C=90^{\circ}-x$, because of the sum of angles in $\triangle A D C, \angle A B C=90^{\circ}-x$, since it is also subtended by $A C$ which subtends $\angle A D C$. Lastly, we can conclude that $\angle B A H=x$, since $\angle A g B=$ $90^{\circ}$, the sum of angles in $\triangle A B g$, implying that $\angle C A O=$ $\angle B A H$.

The reader is challenged to seek even more solutions to this problem as they exist.

\section{THE STATE OF MSTs IN SOUTH AFRICAN MATHEMATICS EDUCATION}

\section{Opportunities Given to Learners}

Most South African learners do not explore multiple solutions to mathematical problems because their teachers lack the expertise of developing MSTs and they are unaware of the significance of MSTs in developing learners' mathematical thought. Hence, many South African learners usually do not achieve near their true mathematical potential because their teachers do not give them adequate support to explore multiple solutions in their classrooms (Donohue \& Borman, 2014; Hoth et al., 2017; Mhlolo, 2017; Oswald \& de Villiers, 2013). After obtaining a solution to a certain problem, South Africa learners usually end there and do not reflect on the solution or look for alternative solutions. If learners can be enculturated into always reflecting and looking for alternative solutions to mathematical problems, their competency in solving mathematics problems would improve. This means that, as these learners grow up, their desire to always reflect on solutions to mathematical problems increase, and unconsciously, they find themselves looking for multiple solutions to mathematical problems in a selfdirected way. As learners are not always forced to find multiple solutions to mathematical problems, the decision to do so becomes their initiative to enhance their competency in solving mathematical problems, because they would be diagnosing their learning, reflecting on which approach is the best and would attempt to utilise different strategies to arrive at the same answer (Knowles, 1975). South African learners should possess mathematical content knowledge of definitions and algorithms for routine problem-solving because it is a necessary requirement for one to display one's mathematical creativity (Leikin \& Lev, 2013). Hence, South African teachers need to transform this ritualistic discourse participation to explorative ones that can support the development of creativity by using MSTs. Though it is argued that classroom practice of the gifted should be different from that of regular classrooms (Leikin, 2010) and that different learners have different instructional needs (Levav-Waynberg \& Leikin, 2012b), in the South African context, teaching methods advocated for teaching gifted learners are perfect for learners considered not gifted (Mhlolo, 2017).

\section{Research Conducted on MSTs}

So far, the significance of MSTs in mathematics and specifically geometry education in general have been discussed. In this section, the nature of research done on MSTs in the South African context is discussed. Though there is a dearth of literature on the significance of MSTs in South African mathematics education, multiple solutions manifest themselves in learners' solutions as observed in their scripts. Specifically, geometry education questions usually end up with more than one solution, different in both approach and structure. Much of the research on MSTs in South Africa is theoretical: the research focuses mainly on showing that a certain national examination problem (Samson, 2015, 2017; Samson \& Kroon, 2019), Olympiad problem (Christison, 2019; De Villiers, 2016, 2017), or a competition problem (Pillay, 2017) have multiple solutions. Though South African researchers collaborate in global empirical studies investigating the effects of MSTs on learners (Daher et al., 2017) and there is a haphazard appearance of the phrase multiple solutions in empirical studies in South Africa (Mhlolo, 2017; Wessels, 2014), there is a lack of empirical studies on the role of MSTs in the South African mathematics education. I am currently not aware of any empirical study in the South African context on the role of MSTs in both teacher and learner education. This raises red flags about both South African teachers' and learners' competency in mathematical problem-solving, because not being engaged in the activity of producing multiple solutions to mathematical problems might mean that they are likely not able solve mathematical problems in various ways. The incorporation of MSTs in both teacher and learner education is critical in the development of their mathematical knowledge (Schukajlow et al., 2015; Stanislaw \& Krug, 2014) and the ability to solve problems in multiple ways is a necessary skill for the 21st century (Gleason, 2018; Organization for Economic Cooperation and Development, 2018). Hence, South African mathematics educators, curriculum designers and other stakeholders should start investigating the possibility of incorporating MSTs in mathematics teaching and learning.

\section{The Significance of MSTs in Teachers and CAPS}

Despite the above-highlighted research on the benefits of MSTs in mathematics education, the use of MSTs in supporting teachers' development of content knowledge and problem solving abilities for competent teaching of mathematics in the South African context is poorly researched. An example of an empirical study on MSTs is that of Mhlolo (2017), who investigated whether South African teachers were able to recognise and support the development of mildly gifted learners' 
creative potential. Four teachers' classroom practice was observed over a week, and the data were analysed based on their representational fluency and their responses to mildly gifted learners' creative ideas (Mhlolo, 2017). The results of the latter study showed that, in South Africa, regular classrooms might not be conducive to the nurturing of mildly gifted learners' creative potential. MSTs are effective in the professional development of pre-service mathematics teachers' (PMTs) and in-service mathematics teachers' knowledge of mathematics, pedagogy and their competence in solving mathematical problems (Chapman, 2013; Guberman \& Leikin, 2013; Leikin, 2007, 2011; Leikin \& Levav-Waynberg, 2008; Stupel \& Ben-Chaim, 2017). After engaging in a course on MSTs practice, in-service teachers began to give novel multiple solutions to mathematical problems and their creativity increased (Guberman \& Leikin, 2013; Stupel \& Ben-Chaim, 2017). MSTs put teachers in a better position to not only reproduce solutions from books or previous experiences but to produce their innovative solution (Guberman \& Leikin, 2013), a practice they can nurture in their learners. Teaching through MSTs is not only effective in developing learners' mathematical thinking but also in improving their problem-solving competency (Lynch \& Star, 2014; Schoenfeld, 1983; Stanislaw \& Krug, 2014). Hence, teachers should organise their mathematical classroom practices such that they incorporate MSTs and train their learners to always reflect on solutions to determine if there is a better, more elegant solution than the one they already found (Santos-Trigo \& Reyes-Rodriguez, 2016).

Recently, South Africa has developed a teaching and learning framework that aims to teach mathematics for understanding (Department of Basic Education, 2019). One of the key principles in this document is to ensure quality mathematics teaching in the classroom to maximise the achievement of the CAPS outcomes and performance in the subject. It uses reflections from countries that perform higher in international tests to guide teachers on how they can support learners' mathematical development to match international standards. The framework states that teachers should strive to:

- develop learners' strategic competence - the ability to formulate, represent and decide on appropriate strategies to solve mathematical problems;

- provide multiple and varied opportunities for learners to develop their mathematical reasoning skills - the capacity for logical thought, reflection, explanation and justification (Department of Basic Education, 2019, p. 13).
However, if teachers strive to give learners opportunities to decide on appropriate strategies they would use to solve mathematical problems, learners need to have more than one problem-solving strategy at their disposal. The current regular teaching in South African schools cannot equip learners with enough problem-solving strategies because it focuses on rote learning. Furthermore, providing learners with multiple and varied opportunities to develop their mathematical thinking cannot be achieved through rote learning in South African classrooms; a learning environment characterised by exploration and reflection is required. Some of these teacher competencies envisaged by the CAPS supporting document are currently difficult to achieve, because CAPS is "structured" and does not afford teachers a chance to use their expertise to teach their learners effectively in their respective contexts. It is challenging to obtain fluidity, as teachers are given work schedules with deadlines for the completion of topics, and in certain situations, details of class and homework activities are offered to teachers to give to learners. Amongst other conclusions, Mhlolo (2017) and Julie and Gierdien (2020) mentioned that South African teachers are usually caught between teaching for mathematical competency and meeting curriculum demands.

\section{CONCLUSIONS AND RECOMMENDATIONS}

Most South African classrooms focus on training learners to pass tests and examinations without sound understanding. Some thinking moves ${ }^{2}$ related to mathematical problem-solving are usually neglected and not nurtured in the performance-based South African mathematics education curriculum. The exercise of finding multiple solutions to mathematical problems is one of these thinking moves. This theoretical article is an attempt to answer the following question: What is the significance of MSTs in mathematics education, and why is it relevant for South African mathematics education to make the exercise of producing multiple solutions accessible to learners? In this exhaustive literature study, I explicated ideas that would help in answering the above question. Before summarising these ideas to answer the above-stated question, the reader should bear in mind that the subsequent conclusions - though they may be of global importance - need to be viewed in the context of South African mathematics education. Furthermore, above I have synthesized the available evidence of the benefits of incorporating mathematics education, the deficiency in this research within South African mathematics education, and I occasionally linked my discussion with the context of South Africa. In

\footnotetext{
${ }^{2}$ Here I use the phrase "thinking moves" to refer to the shifts in mathematical thinking. These thinking shifts are related to beliefs about mathematical problem solving, for example, one may have the belief that to solve mathematical problems certain procedures need to be followed and if these procedures are not followed then the problem cannot be solved. This also include beliefs about what constitutes as a mathematical problem and a mathematical solution to a problem.
} 
this conclusion I mainly aim to provide recommendations towards the second part of my proposed question, why is it relevant for South African mathematics education to make the exercise of producing multiple solutions accessible to learners?

Children go to school so that teachers can facilitate their holistic development, train them to be productive individuals and to become innovators so that they can one day support their families. In the teachers' possession, children's minds are malleable, ready to be shaped into various objects through appropriate teaching methods (Kilpatrick, 1985). Since the development of children is generational, it is argued that mathematics education should allow learners to develop and be competent in mathematics-specific skills that would allow them to flourish in the 21st century. I regard the incorporation of MSTs in mathematics education as promising in developing several 21st-century skills, such as solving problems in different ways, creativity, innovation, collaboration, and higher order thinking. Given the benefits of incorporating MSTs to enhance mathematical thinking, problem-solving and performance, it suffices to begin investigating this dormant field in the South African context. To transform classrooms into meaningful learning environments and to teach mathematics as a creative enterprise, teachers are encouraged to design rich problems containing multiple solutions and support learners in finding these multiple solutions (or proofs). The incorporation of MSTs further presents a window for teachers to spot those learners who might be creative in producing multiple solutions to mathematical problems and to train them to compete in mathematics Olympiads with their global counterparts.

Comparing his arguments with those of Hamming (1980), Jeremy Kilpatrick (1981) provided reasons as to why research in mathematics education is not effective something that is still visible nowadays. He mentioned the lack of ingenuity in adapting and linking our research tools or instruments to the problems faced in real classrooms. Kilpatrick (1981) lamented that most mathematics education research is not effective because it reveals little implications for classroom practice. Encouraging learners to produce multiple solutions to mathematics problems can engage them in reflective activity (Dewey, 1933), which can innovate their individual and country`s social progress (Schon, 1983). It has been observed that children benefit easily through studying behaviour modelled by influential adults, like their teachers (Cropley, 1997). It is in their nature to learn from adults from an early age. In the light of this, there is a dire need for teacher training institutions to develop mathematics teachers who can design and produce multiple solutions to mathematical problems. This behaviour should further be modelled in the classroom where learners can see the significance of producing multiple solutions to mathematical problems.
Currently, I am aware of legitimate concerns in South African education. One particular concern is that teachers are required to employ time-consuming innovative teaching strategies under strict and imposed time frames. In this way, teachers are required to balance high-quality teaching with curriculum coverage according to the CAPS mandate, which leaves them in a bewildered state between teaching for understanding and teaching for learners to pass the national examinations (Julie \& Gierdien, 2020; Mhlolo, 2017). This concern, and others not mentioned here, point to the significance of including curriculum designers and other stakeholders in designing a mathematics curriculum that incorporates MSTs. This is because the benefits of incorporating MSTs in mathematics education outweigh the detriments of not doing so.

The propositions above stem from decades of empirical and theoretical research on mathematics education discussed in this article. These propositions are mainly framed by the growing demand for education to train learners to acquire certain skills that would allow them to function as productive citizens in 21st-century bombarded by digitisation and automation. Furthermore, the propositions are formulated to improve the dire situation of poor performance in South African mathematics education, which is currently not preparing South African learners for the 21st century and the workplace. Despite the perennial poor performance in both national and international tests, South African mathematics education has not adapted to improve this situation and meet global standards. In this article, I entered a field dormant in South African research to articulate the importance of MSTs in 21stcentury mathematics education and to provide reasons as to why South African mathematics education must adopt an approach that focuses on engaging learners in MSTs. Within this field, two other important issues were also raised: (a) teacher training institutions need to train mathematics teachers who would be competent in formulating, producing and facilitating the teaching and learning of mathematics using MSTs; and (b) South African mathematics educational researchers need to conduct empirical studies to investigate the role of MSTs in both teacher and learner education. It is hoped that this article is sufficient to ignite a local debate on the suitability of MSTs in the context of South Africa and the suitability of MSTs in training South African learners to be successful in the 21st century.

\section{REFERENCES}

Alex, J. K. (2019). The preparation of secondary school mathematics teachers in South Africa: Prospective teachers' student level disciplinary content knowledge. Eurasia Journal of Mathematics, Science and Technology Education, 15(12), em1791. https:// doi.org/10.29333/ejmste/105782 
Alex, J. K., \& Mammen, K. J. (2014). An Assessment of the Readiness of Grade 10 Learners for Geometry in the Context of Curriculum and Assessment Policy Statement (CAPS) Expectation. International Journal of Educational Sciences, 7(1), 29-39. https:/ / doi.org/10.1080/09751122.2014.11890167

Anderson, H. H. (1960). The Nature of Creativity. Studies in Art Education, 1(2), 10-17. https:/ / doi.org/10.2307/1319842

Apino, E., \& Retnawati, H. (2017). Developing Instructional Design to Improve Mathematical Higher Order Thinking Skills of Students. Journal of Physics: Conference Series, 812, 012100. https: / / doi.org/10.1088/1742-6596/812/1/012100

Arends, F., Winnaar, L., \& Mosimege, M. (2017). Teacher classroom practices and mathematics performance in South African schools: A reflection on TIMSS 2011. South African Journal of Education, 37(3), 1-11.

Bayaga, A., Mthethwa, M. M., Bosse, M. J., \& Williams, D. (2019). Impacts of implementing GeoGebra on eleventh grade student's learning of Euclidean geometry. South African Journal of Higher Education, 33(6).

Bingolnali, E. (2011). Multiple Solutions to Problems in Mathematics Teaching: Do Teachers Really Value Them? Australian Journal of Teacher Education, 36(1), 18-31.

Chapman, O. (2013). Mathematical-task knowledge for teaching. Journal of Mathematics Teacher Education, 16(1), 1-6. https:// doi.org/10.1007/s10857-0139234-7

Chen, E. (2016). Euclidean geometry in mathematical olympiads. United States of America: The Mathematical Association of America (Incorporated).

Christison, A. (2019). A look back : the International Mathematics Olympiad, 1959. Learning and Teaching Mathematics, 2019(27), 26-29. Retrieved from https://journals.co.za/content/journal/10520/EJ C-19eb16bb03

Cropley, A. J. (1997). More ways than one: Fostering creativity. Norwood, New Jersey: Ablex Publishing Corporation.

Daher, W., Tabaja-Kidan, A., \& Gierdien, F. (2017). Educating Grade 6 students for higher-order thinking and its influence on creativity. Pythagoras, 38(1), 350 2017. https://doi.org/10.4102/ pythagoras.v38i1.350

De Villiers, M. (2004a). The role and function of quasiempirical methods in mathematics. Canadian Journal of Science, Mathematics and Technology Education, 4(3), 397-418. https://doi.org/10.1080/ 14926150409556621

De Villiers, M. (2004b). Using dynamic geometry to expand mathematics teachers' understanding of proof. International Journal of Mathematical Education in Science and Technology, 35(5), 703-724. https:/ / doi.org/10.1080/0020739042000232556

De Villiers, M. (2016). A multiple solution task: A SA mathematics olympiad problem. Learning $\mathcal{E}$ Teaching Mathematics, (20), 18-20.

De Villiers, M. (2017). A multiple solution task : another SA Mathematics Olympiad problem. Learning and Teaching Mathematics, 2017(22), 42-46. Retrieved from https://journals.co.za/content/journal/ 10520/EJC-7c1634cc0

De Villiers, M., \& Heideman, N. (2014). Conjecturing, refuting and proving within the context of dynamic geometry. Learning and Teaching Mathematics, 2014(17), 20-26. Retrieved from https://journals. co.za/content/amesal/2014/17/EJC164266

Department of Basic Education. (2011). Curriculum and Assessment Policy Statement: Mathematics (Grade 1012). Pretoria: Government Printers

Department of Basic Education. (2017). The SACMEQ IV project in South Africa: A study of the conditions of schooling and the quality of education. South Africa

Department of Basic Education. (2019). Mathematics teaching and learning framework in South Africa: Teaching mathematics for understanding. Pretoria: Government Printers

Dewey, J. (1933). How we think: A restatement of the relation of reflective thinking to the educative process. Boston: D. C. Heath and Company.

Dhombres, J. (1993). Is one proof enough? Travels with a mathematician of the baroque period. Educational Studies in Mathematics, 24(4), 401-419. https:/ / doi.org/10.1007/BF01273373

Donohue, D., \& Borman, J. (2014). The challenges of realising inclusive education in South Africa. South African Journal of Education, 34(2), 1-14.

Erbas, A. K., \& Okur, S. (2012). Researching students' strategies, episodes, and metacognitions in mathematical problem solving. Quality $\mathcal{E}$ Quantity, 46(1), 89-102. https:/ / doi.org/10.1007/s11135-0109329-5

Ervynck, G. (1991). Mathematical Creativity. In D. Tall (Ed.), Advanced Mathematical Thinking (pp. 42-53). Dordrecht: Springer Netherlands.

Flavell, J. H. (1976). Metacognitive aspects of problem solving. In L. Resnick (Ed.), The nature of intelligence (pp. 231-236). Hillside, NJ: Erlbaum.

Flavell, J. H. (1979). Metacognition and cognitive monitoring: A new are of cognitive-developmental inquiry. American Psychologist, 34(10), 906-911.

Gleason, N. W. (2018). Singapore's Higher Education Systems in the Era of the Fourth Industrial Revolution: Preparing Lifelong Learners. In N. W. Gleason (Ed.), Higher Education in the Era of the 
Fourth Industrial Revolution (pp. 145-169). Singapore: Springer Singapore.

Große, C. S. (2014). Mathematics learning with multiple solution methods: effects of types of solutions and learners' activity. Instructional Science, 42(5), 715745. Retrieved from www.jstor.org/stable/ 43575255

Guberman, R., \& Leikin, R. (2013). Interesting and difficult mathematical problems: changing teachers' views by employing multiple-solution tasks. Journal of Mathematics Teacher Education, 16(1), 33-56. https:/ / doi.org/10.1007/s10857-012-9210-7

Guilford, J. P. (1967). Creativity: Yesterday, Today and Tomorrow. The Journal of Creative Behavior, 1(1), 314. https:/ / doi.org/10.1002/j.2162-6057.1967.tb000 02. $x$

Hadamard, J. (1945). The psychology of invention in the mathematical field: Princeton University Press.

Hamming, R. W. (1980). The Unreasonable Effectiveness of Mathematics. The American Mathematical Monthly, 87(2), 81-90. https://doi.org/10.2307/ 2321982

Hashimoto, Y. (1997). The methods of fostering creativity through mathematical problem solving. ZDM, 29(3), 86-87. https://doi.org/10.1007/ s11858-997-0005-8

Hoth, J., Kaiser, G., Busse, A., Döhrmann, M., König, J., \& Blömeke, S. (2017). Professional competences of teachers for fostering creativity and supporting high-achieving students. ZDM, 49(1), 107-120. https:// doi.org/10.1007/s11858-016-0817-5

Howie, S. J. (2003). Language and other background factors affecting secondary pupils' performance in Mathematics in South Africa. African Journal of Research in Mathematics, Science and Technology Education, 7(1), 1-20. https://doi.org/10.1080/ 10288457.2003.10740545

Julie, C., \& Gierdien, F. (2020). Reflections on Realistic Mathematics Education from a South African Perspective. In M. van den Heuvel-Panhuizen (Ed.), International Reflections on the Netherlands Didactics of Mathematics: Visions on and Experiences with Realistic Mathematics Education (pp. 71-82). Cham: Springer International Publishing.

Kilpatrick, J. (1981). The Reasonable Ineffectiveness of Research in Mathematics Education. For the Learning of Mathematics, 2(2), 22-29. Retrieved from www.jstor.org/stable/40247734

Kilpatrick, J. (1985). Reflection and recursion. Educational Studies in Mathematics, 16(1), 1-26. https:/ / doi.org/ 10.1007/BF00354880

Knowles, M. S. (1975). Self-directed learning: A guide for learners and teachers. Englewood Cliffs, NJ: Cambridge Adult Education.
Leikin, R. (2007). Habits of the mind associated with advanced mathematical thinking and solution spaces of mathematical tasks. Paper presented at the Proceedings of the fifth conference of the European Society fo Research in Mathematics Education CERME-5.

Leikin, R. (2010). Teaching the Mathematically Gifted. Gifted Education International, 27(2), 161-175. https:/ / doi.org/10.1177/026142941002700206

Leikin, R. (2011). Multiple-solution tasks: from a teacher education course to teacher practice. ZDM, 43(6), 993-1006. https://doi.org/10.1007/s11858-0110342-5

Leikin, R. (2014). Challenging Mathematics with Multiple Solution Tasks and Mathematical Investigations in Geometry. In Y. Li, E. A. Silver, \& S. Li (Eds.), Transforming Mathematics Instruction: Multiple Approaches and Practices (pp. 59-80). Cham: Springer International Publishing.

Leikin, R., \& Lev, M. (2013). Mathematical creativity in generally gifted and mathematically excelling adolescents: what makes the difference? ZDM, 45(2), 183-197. https://doi.org/10.1007/s11858012-0460-8

Leikin, R., \& Levav-Waynberg, A. (2008). Solution Spaces of Multiple-Solution Connecting Tasks as a Mirror of the Development of Mathematics Teachers' Knowledge. Canadian Journal of Science, Mathematics and Technology Education, 8(3), 233-251. https:// doi.org/10.1080/14926150802304464

Leikin, R., \& Pitta-Pantazi, D. (2013). Creativity and mathematics education: the state of the art. ZDM, 45(2), 159-166. https://doi.org/10.1007/s11858012-0459-1

Levav-Waynberg, A., \& Leikin, R. (2012a). The role of multiple solution tasks in developing knowledge and creativity in geometry. The Journal of Mathematical Behavior, 31(1), 73-90. https:// doi.org/10.1016/j.jmathb.2011.11.001

Levav-Waynberg, A., \& Leikin, R. (2012b). Using Multiple Solution Tasks for the Evaluation of Students' Problem-Solving Performance in Geometry. Canadian Journal of Science, Mathematics and Technology Education, 12(4), 311-333. https:/ / doi.org/10.1080/14926156.2012.732191

Lockhart, P. (2009). A mathematician`s lament. New York: Bellevue Literary Press.

Lynch, K., \& Star, J. R. (2014). Teachers' Views About Multiple Strategies in Middle and High School Mathematics. Mathematical Thinking and Learning, 16(2), 85-108. https://doi.org/10.1080/10986065. 2014.889501

Mann, E. L. (2006). Creativity: The Essence of Mathematics. Journal for the Education of the Gifted, 
30(2), 236-260. https://doi.org/10.4219/jeg-2006264

Mhlolo, M. K. (2017). Regular classroom teachers' recognition and support of the creative potential of mildly gifted mathematics learners. ZDM, 49(1), 8194. https:/ / doi.org/10.1007/s11858-016-0824-6

Miri, B., David, B.-C., \& Uri, Z. (2007). Purposely Teaching for the Promotion of Higher-order Thinking Skills: A Case of Critical Thinking. Research in Science Education, 37(4), 353-369. https: / / doi.org/10.1007/s11165-006-9029-2

Naidoo, J., \& Kapofu, W. (2020). Exploring female learners' perceptions of learning geometry in mathematics. South African Journal of Education, 40, 1-11. Retrieved from http://www.scielo.org.za/ scielo.php?script=sci_arttext\&pid=S0256-

01002020000100014\&nrm=iso

National Council of Teachers of Mathematics. (2000). Principles and standards for school mathematics. Reston, VA: Author.

Organization for Economic Co-operation and Development. (2018). PISA 2021 mathematics framework (draft). Retrieved from https: / pisa2021maths.oecd.org/\#Formulate

Oswald, M., \& de Villiers, J.-M. (2013). Including the gifted learner: perceptions of South African teachers and principals. South African Journal of Education, 33, 1-21. Retrieved from http:/ / www.scielo.org.za/scielo.php?script=sci_a rttext\&pid=S0256-01002013000100004\&nrm=iso

Pehkonen, E. (1997). The state-of-art in mathematical creativity. ZDM, 29(3), 63-67. https://doi.org/ $10.1007 / \mathrm{s} 11858-997-0001-Z$

Pfeiffer, S. I., \& Blei, S. (2008). Gifted Identification Beyond the IQ Test: Rating Scales and Other Assessment Procedures. In S. I. Pfeiffer (Ed.), Handbook of Giftedness in Children: Psychoeducational Theory, Research, and Best Practices (pp. 177-198). Boston, MA: Springer US.

Phakeng, M. S., \& Moschkovich, J., N. (2013). Mathematics Education and Language Diversity: A Dialogue across Settings. Journal for Research in Mathematics Education, 44(1), 119-128. https:/ / doi.org/10.5951/jresematheduc.44.1.0119

Pillay, P. (2017). A multiple solution problem. Learning $\mathcal{E}$ Teaching Mathematics, 23, 32-37.

Poincare, H. (1948). Science and method. New York: Dover.

Polya, G. (1954). Mathematics and plausible reasoning: Induction and analogy in mathematics (Vol. 2). Princeton: Princeton University Press.

Polya, G. (1973). How to solve it: A new aspect of mathematics method. Princeton: Princeton University Press.
Pournara, C., Hodgen, J., Adler, J., \& Pillay, V. (2015). Can improving teachers' knowledge of mathematics lead to gains in learners' attainment in Mathematics? South African Journal of Education, 35, 1-10. Retrieved from http://www.scielo.org.za/ scielo.php?script=sci_arttext\&pid=S0256$01002015000300007 \& n r m=$ iso

Reddy, V., Visser, M., Winnaar, L., Arends, F., Juan, A., Pronsloo, C., \& Isdale, K. (2016). TIMSS 2015: Highlights of mathematics and science achievement of grade 9 South African learners.

Renzulli, J. S. (2011). What Makes Giftedness?: Reexamining a Definition. Phi Delta Kappan, 92(8), 81-88.

https:/ / doi.org/10.1177/003172171109200821

Resnick, L. (1987). Education and learning to think. Washington, DC: National Academy.

Rittle-Johnson, B., Star, J. R., \& Durkin, K. (2012). Developing procedural flexibility: Are novices prepared to learn from comparing procedures? British Journal of Educational Psychology, 82(3), 436455. https://doi.org/10.1111/j.2044-8279.2011.02 037.x

Runco, M. A. (1993). Creativity as an educational objective for disadvantaged students. Storrs: University of Connecticut: The National Research Center on the Gifted and Talented.

Runco, M. A., \& Acar, S. (2012). Divergent Thinking as an Indicator of Creative Potential. Creativity Research Journal, 24(1), 66-75. https://doi.org/ 10.1080/10400419.2012.652929

Samson, D. (2015). Devising explorative Euclidean Geometry questions. Learning and Teaching Mathematics, 2015(19), 13-16. Retrieved from https:/ /journals.co.za/content/amesal/2015/19/ EJC181296

Samson, D. (2017). Euclidean geometry - Nurturing multiple solutions. Learning $\mathcal{E}$ Teaching Mathematics, 23, 15-18.

Samson, D., \& Kroon, S. (2019). A multiple solution task. Learning and Teaching Mathematics, 2019(26), 7-11. Retrieved from https://journals.co.za/content/ journal/10520/EJC-16d84dd913

Santos-Trigo, M., \& Reyes-Rodriguez, A. (2016). The use of digital technology in finding multiple paths to solve and extend an equilateral triangle task. International Journal of Mathematical Education in Science and Technology, 47(1), 58-81. https: / / doi.org/10.1080/0020739X.2015.1049228

Schindler, M., Joklitschke, J., \& Rott, B. (2018). Mathematical Creativity and Its SubdomainSpecificity. Investigating the Appropriateness of Solutions in Multiple Solution Tasks. In F. M. Singer (Ed.), Mathematical Creativity and Mathematical Giftedness: Enhancing Creative 
Capacities in Mathematically Promising Students (pp. 115-142). Cham: Springer International Publishing.

Schoenfeld, A. H. (1983). Problem solving in the mathematics curriculum: A report, recommendations' and an annotated bibliography. Washington, DC: The Mathematical Association of America.

Schoenfeld, A. H. (1985). Mathematical problem sovling. Orlando: Academic Press, Inc.

Schoenfeld, A. H. (1992). Learning to think mathematically: Problem solving, metacognition, and sense making in mathematics. In D. Grouws (Ed.), Handbook for research on mathematics teaching and learning (pp. 334-370). New York: Macmillan.

Schon, D. A. (1983). The reflective practitioner: How professionals think in action. United States of America: Basic Books.

Schukajlow, S., Krug, A., \& Rakoczy, K. (2015). Effects of prompting multiple solutions for modelling problems on students' performance. Educational Studies in Mathematics, 89(3), 393-417. https: / / doi.org/10.1007/s10649-015-9608-0

Segal, R., Stupel, M., \& Flores, A. (2017). Examples of multiple proofs in geometry: Part 1 , tasks and hints. Ohio Journal of School Mathematics, 35-43.

Sigler, A., Segal, R., \& Stupel, M. (2016). The standard proof, the elegant proof, and the proof without words of tasks in geometry, and their dynamic investigation. International Journal of Mathematical Education in Science and Technology, 47(8), 1226-1243. https:/ / doi.org/10.1080/0020739X.2016.1164347

Silver, E. A. (1997). Fostering creativity through instruction rich in mathematical problem solving and problem posing. ZDM, 29(3), 75-80. https:/ / doi.org/10.1007/s11858-997-0003-x

Sriraman, B. (2005). Are Giftedness and Creativity Synonyms in Mathematics? Journal of Secondary Gifted Education, 17(1), 20-36. https://doi.org/ 10.4219/jsge-2005-389

Sriraman, B. (2009). The characteristics of mathematical creativity. ZDM, 41(1), 13. https://doi.org/ $10.1007 / \mathrm{s} 11858-008-0114-\mathrm{Z}$

Sriraman, B., \& Dickman, B. (2017). Mathematical pathologies as pathways into creativity. ZDM, 49(1), 137-145. https://doi.org/10.1007/s11858016-0822-8

Sriraman, B., Haavold, P., \& Lee, K. (2013). Mathematical creativity and giftedness: a commentary on and review of theory, new operational views, and ways forward. ZDM, 45(2), 215-225. https://doi.org/ 10.1007/s11858-013-0494-6

Stanislaw, S., \& Krug, A. (2014). Do Multiple Solutions Matter? Prompting Multiple Solutions, Interest,
Competence, and Autonomy. Journal for Research in Mathematics Education, 45(4), 497-533. https:/ / doi.org/10.5951/jresematheduc.45.4.0497

Stols, G., Ferreira, R., Pelser, A., Olivier, W. A., Van der Merwe, A., De Villiers, C., \& Venter, S. (2015). Perceptions and needs of South African Mathematics teachers concerning their use of technology for instruction. South African Journal of Education, 35, 01-13. Retrieved from http:/ / www.scielo.org.za/ scielo.php?script=sci_a rttext\&pid=S0256-01002015000400004\&nrm=iso

Stols, G., Van Putten, S., \& Howie, S. (2010). Making Euclidean geometry compulsory: are we prepared? Perspectives in Education, 28(4), 22-31. Retrieved from https://www.ingentaconnect.com/content/ sabinet/persed/2010/00000028/00000004/art0000 4

Stupel, M., \& Ben-Chaim, D. (2017). Using multiple solutions to mathematical problems to develop pedagogical and mathematical thinking: A case study in a teacher education program. Investigations in Mathematics Learning, 9(2), 86-108. https:/ / doi.org/10.1080/19477503.2017.1283179

Torrance, E. P. (1966). Torrance tests of creative thinking. Norms-technical manual. Research edition. Verbal tests, forms $A$ and B. Figural tests, forms $A$ and B. Princeton: Personnel Press.

Ubah, I., \& Bansilal, S. (2019). The use of semiotic representations in reasoning about similar triangles in Euclidean geometry. Pythagoras, 40(1), 4802019. https:/ / doi.org/10.4102/ pythagoras.v40i1.480

Umugiraneza, O., Bansilal, S., \& North, D. (2018). Exploring teachers' use of technology in teaching and learning mathematics in KwaZulu-Natal schools. Pythagoras, 39(1), 3422018. https:/ / doi.org/10.4102/ pythagoras.v39i1.342

Visser, M., Juan, A., \& Feza, N. (2015). Home and school resources as predictors of mathematics performance in South Africa. South African Journal of Education, 35(1), 1-10.

Weisberg, R. W. (1988). Problem solving and creativity. In R. J. Sternberg (Ed.), The nature of creativity (pp. 148-176). New York: Cambridge University Press.

Wessels, H. M. (2014). Levels of mathematical creativity in model-eliciting activities. Journal of Mathematical Modelling and Application, 1(9), 22-40.

Winner, E. (2000). The origins and ends of giftedness. American Psychologist, 55(1), 159-169.

World Economic Forum. (2015). The global competitiveness repot 2015-2016. Retrieved from http://www3. weforum.org/docs/gcr/2015-2016/Global_ Competitiveness_Report_2015-2016.pdf 